\title{
Chaetocladius Kieffer (Diptera: Chironomidae) in China
}

\author{
Qian Wang, Fanqing Kong \& Xinhua Wang*
}

\begin{abstract}
Wang, Q., Kong, F. \& Wang, X. 2012: Chaetocladius Kieffer (Diptera: Chironomidae) in China. - Entomol. Fennica 23: 42-48.

Chaetocladius Kieffer in China is reviewed and a key to the males is provided. There are five Chinese species, of which three are described and illustrated as adult males: C. absolutus Wang, Kong \& Wang, sp. n., C. tibetensis Wang, Kong \& Wang, sp. n. and C. triquetrus Wang, Kong \& Wang, sp. n. Chaetocladius oyabevenustus Sasa, Kawai \& Ueno is recorded from China for the first time.

Q. Wang, College of Life Sciences, Nankai University, 300071 Tianjin, China \& Tianjin Key Laboratory of Aqua-Ecology \& Aquaculture, Department of Fisheries Science, Tianjin Agricultural University, 300384, Tianjin, China; E-mail: wqgt1999@yahoo.com.cn

F. Kong, College of Life Sciences, Nankai University, 300071 Tianjin, China

$X$. Wang (*corresponding author), College of Life Sciences, Nankai University, 300071 Tianjin, China; E-mail: xhwang@nankai.edu.cn
\end{abstract}

Received 7 June 2011, accepted 2 November 2011

\section{Introduction}

The genus Chaetocladius was established by Kieffer in 1911, with Dactylocladius setiger Kieffer as the type species. The immature stages of Chaetocladius are found in a wide variety of semiaquatic and truly aquatic habitats, mainly in alpine, arctic or subarctic areas of the Holarctic and Afrotropical regions. However, Chaetocladius on the whole as well as a number of species within it have been in dire need of revision for a long time. Based on the double or single gonostylus, with or without crista dorsalis and virga, the genus can be divided into two subgenera, $C$. ( $A m$ blycladius Kieffer) and C. (Chaetocladius) (Sæther 1986). C. (Amblycladius) includes C. (Amblycladius) subplumosus Kieffer only, while C. (Chaetocladius) can be divided into four species groups based on the immature stages, the dentiforceps, piger, vitellinus and acuticornus groups, while this is only partly sustained by the adult males (Cranston et al. 1983, Cranston \& Martin 1989, Stur \& Spies 2011).
Chaetocladius is a species rich genus of the subfamily Orthocladiinae with a worldwide distribution. Up to date, the genus comprises 55 recorded species: 49 species in the Palaearctic region, 6 in the Nearctic region, 1 in the Oriental region, 2 in the Afrotropical region (Sublette \& Sublette 1973, Cranston \& Martin 1989, Ashe \& Cranston 1990, Oliver et al. 1990, Harrison 1992, Wang 2000, Chaudhuri 2001, Yamamoto 2004, Makarchenko 2004, 2011, Stur \& Spies 2011).

Wang (2000) recorded only one species of this genus from China, $C$. dentiforceps Edwards. In this paper an additional three new species are described and illustrated. Five species from China can be included in the subgenus $C$. (Chaetocladius). A key to the males of Chaetocladius from China is presented.

\section{Material and methods}

The morphological nomenclature used in this paper follows Sæther (1980). Abbreviations used in 
Table 1. Abbreviations used in present study.

\begin{tabular}{|c|c|}
\hline fe, ti, ta - ta $_{5}$ & $\begin{array}{l}\text { Femur, tibia and tarsal segments } 1-5 \\
\text { Legs } 1-3\end{array}$ \\
\hline $\begin{array}{l}p_{1}-p_{3} \\
R\end{array}$ & Vein radius of wing, which splits into branches $R_{1}, R_{2+3}$ and $R_{4+5}$ \\
\hline AR & $\begin{array}{l}\text { Antennal ratio: ratio of length of apical elongated flagellomere plus any flagellomeres distal } \\
\text { to it divided by combined length of the more basal flagellomeres }\end{array}$ \\
\hline VR & $\begin{array}{l}\text { Venarum ratio: ratio of length of } \mathrm{Cu} \text { to length of } \mathrm{M} \text {; Cu: vein cubitus of wing, often splitting } \\
\text { into two branches; } \mathrm{M} \text { : vein media of wing, usually situating in middle and below vein } \mathrm{R}\end{array}$ \\
\hline LR & Leg ratio: ratio of metetarsus to tibia \\
\hline BV & $\begin{array}{l}\text { "Beinverhältnisse": combined length of femur, tibia and basitarsus divided by combined } \\
\text { length of tarsomeres } 2-5\end{array}$ \\
\hline SV & "Schenkel-Schiene-Verhältnis": ratio of femur plus tibia to metatarsus \\
\hline BR & $\begin{array}{l}\text { Bristle ratio: ratio of longest seta of ta } 1 \text { divided by minimum width of ta }{ }_{1} \text { measured one third } \\
\text { from apex }\end{array}$ \\
\hline HR & Hypopygium ratio: ratio of length of gonocoxite to the length of gonostylus \\
\hline $\mathrm{HV}$ & Hypopygium value: ratio of total length to length of gonostylus times 10 \\
\hline
\end{tabular}

this paper are explained in Table 1. The material examined was mounted on slides following the procedure outlined by Sæther (1969). Measurements are given as ranges followed by the arithmetic mean, when there are three or more specimens measured, followed by the number measured $(n)$ in parentheses. All types are deposited in the College of Life Sciences, Nankai University, China (BDN).

\section{Taxonomy}

\subsection{Chaetocladius absolutus Wang, Kong \& Wang, sp. n. Fig. 1}

Type material. Holotype male (BDN No. 012), CHINA: Tibet, Mt. Shergmla, west side (29³9' $\left.\mathrm{N}, 91^{\circ} 09^{\prime} \mathrm{E}\right)$, sweeping net, 1 male, 29.IX.1997, T. Solhøy \& J. Skartveit leg.

Diagnostic characters. C. absolusus sp. n., by having nearly circular inferior volsella, can be separated from other known species of the genus, except $C$. artistylus Bhattacharyay Chaudhuri, 1993. From the latter it can be separated by its virga composed of tapering spines and well developed anal lobe.

Description. Measurements ( $n=1$ male). Total length $4.75 \mathrm{~mm}$. Wing length $3.35 \mathrm{~mm}$. Total length / wing length 1.42. Wing length / length of profemur 2.91.

Coloration. Head and thorax brown, and abdomen yellowish brown. Wing nearly transparent.

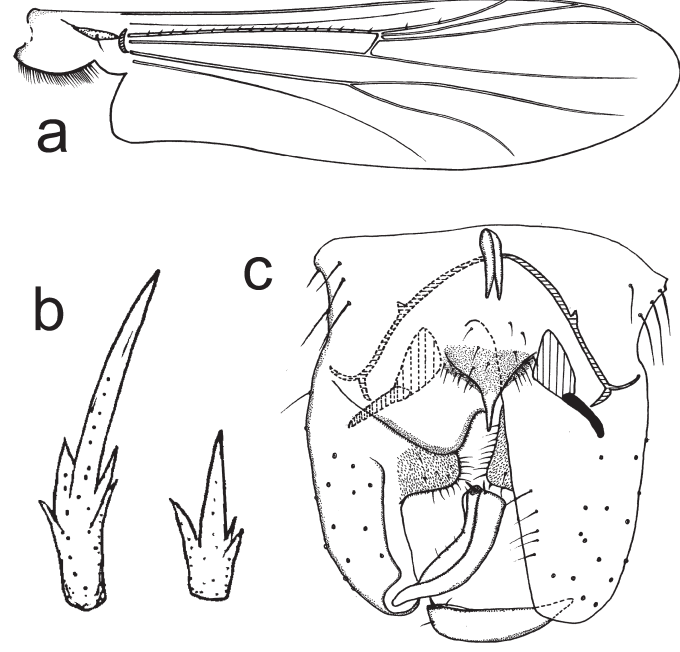

Fig. 1. Chaetocladius absolutus Wang, Kong \& Wang, sp. n. - a. Wing. - b. Spurs of posterior tibia. - c. Hypopygium.

Head. AR 2.57. Temporal setae 12 including 7 inner verticals, 3 outer verticals and 2 postorbitals. Clypeus with 14 setae. Tentorium 210 $\mu \mathrm{m}$ long, 50 wide. Palpomere lengths (in $\mu \mathrm{m}$ ): 17 , $29,114,88,132$. Length ratio of palpomeres $5 / 3$ 1.16 .

Wing (Fig. 1a). Scarcely punctate. Anal lobe well developed. VR 1.0. Costal extension $50 \mu \mathrm{m}$ long. $\mathrm{R}$ with 19 setae, $\mathrm{R}_{1}$ with 2 setae. Brachiolum with 1 setae. Squama with 32 setae.

Thorax. Dorsocentrals 12, acrostichals 10, prealars 7, scutellars 9 .

Legs. Spur of fore tibia $95 \mu \mathrm{m}$ long, of mid tibia $26 \mu \mathrm{m}$ and $29 \mu \mathrm{m}$ long, of hind tibia (Fig. 1b) 
Table 2. Lengths (in $\mu \mathrm{m}$ ) and proportions of leg segments of male Chaetocladius absolutus Wang, Kong \& Wang, sp. n. For abbreviations, see Table 1.

\begin{tabular}{|c|c|c|c|c|c|c|c|c|c|c|c|}
\hline & fe & $\mathrm{ti}$ & $\mathrm{ta}_{1}$ & $\mathrm{ta}_{2}$ & $\mathrm{ta}_{3}$ & $\mathrm{ta}_{4}$ & $\mathrm{ta}_{5}$ & LR & BV & SV & $\mathrm{BR}$ \\
\hline$p_{1}$ & 1,150 & 1,450 & 1,125 & 575 & 450 & 275 & 150 & 0.78 & 2.57 & 2.31 & 1.64 \\
\hline $\mathrm{p}_{2}$ & 1,230 & 1,400 & 740 & 410 & 310 & 210 & 140 & 0.53 & 3.15 & 3.55 & 1.67 \\
\hline$p_{3}$ & 1,330 & 1,700 & 1,010 & 590 & 420 & 260 & 160 & 0.59 & 2.83 & 3.00 & 2.38 \\
\hline
\end{tabular}

$80 \mu \mathrm{m}$ and $30 \mu \mathrm{m}$ long, lateral denticles strong. Tibial comb $48 \mu \mathrm{m}$ long. Pseudospur of mid ta 30 $\mu \mathrm{m}$ and $31 \mathrm{~mm}$ long, of $\mathrm{ta}_{2} 30 \mu \mathrm{m}$ and $33 \mathrm{~mm}$ long, of ta $23 \mathrm{~mm}$ long; of hind ta $28 \mu \mathrm{m}$ and 30 $\mu \mathrm{m}$ long, of $\operatorname{ta}_{2} 29 \mu \mathrm{m}$ and $31 \mu \mathrm{m}$ long, of ta 25 mm long. Width at apex of fore tibia $50 \mu \mathrm{m}$, of mid tibia $48 \mu \mathrm{m}$, of hind tibia $50 \mu \mathrm{m}$. Lengths (in $\mu \mathrm{m})$ and proportions of legs in Table 2.

Hypopygium (Fig. 1c). Anal point slender 50 $\mu \mathrm{m}$ long, $53 \mu \mathrm{m}$ wide at the base, with 7 setae on it. Laterosternite IX with 6 setae. Phallapodeme $93 \mu \mathrm{m}$ long; transverse sternapodeme $138 \mu \mathrm{m}$ long. Virga $60 \mu \mathrm{m}$ long, composed of tapering spines. Gonocoxite $211 \mu \mathrm{m}$ long. Inferior volsella single, semicircular, with 14 long setae. Gonostylus $110 \mu \mathrm{m}$ long, with short crista dorsalis. Megaseta $13 \mu \mathrm{m}$ long. HR 1.92, HV 4.32.

Distribution. Collected in Tibet Autonomous Region in Oriental China.

Etymology. From Latin, absolute, which means developed and refers to the wing with developed anal lobe.

\subsection{Chaetocladius dentiforceps (Edwards)}

Spaniotoma dentiforceps Edwards, 1929: 346. Chaetocladius dentiforceps (Edwards), Wang 2000: 635 .

Material examined. Inner Mongolia Autonomous Region, Mordaga National Forest Park (51 $\left.{ }^{\circ} 14^{\prime} \mathrm{N}, 120^{\circ} 46^{\prime} \mathrm{E}\right)$, sweeping net, 1 male, 8.VII.1988, W. Bu leg.

Diagnostic characters. The species can be separated from other members of the genus by having small anal point and small inferior volsella, gonostylus nearly right angled at the end, and length ratio of palpomeres $5 / 3<1$.

Description. Measurements ( $n=1$ male). Total length $3.37 \mathrm{~mm}$. Wing length $2.18 \mathrm{~mm}$. Total length / wing length 1.55. Antenna with 13 flagellomeres; AR 1.70. Anal lobe weakly developed, VR 1.05. R with 6 setae, $R_{1}$ with 1 seta. Anal point short, about $25 \mu \mathrm{m}$ long, with 8 setae on it. Laterosternite IX with 8 setae. Phallapodeme $80 \mu \mathrm{m}$ long; transverse sternapodeme $100 \mu \mathrm{m}$ long. Virga $40 \mu \mathrm{m}$ long. Gonocoxite 207 $\mu \mathrm{m}$ long. Inferior volsella small, with 10 setae on it. Gonostylus $92 \mu \mathrm{m}$ long. Megaseta $11 \mu \mathrm{m}$ long. HR 2.25, HV 3.67.

Distribution. Recorded in Europe. Occurs in Palaearctic (Inner Mongolia Autonomous Region) China.

\subsection{Chaetocladius oyabevenustus Sasa, Kawai \& Ueno}

Chaetocladius oyabevenustus Sasa, Kawai \& Ueno 1988: 50; Yamamoto 2004: 13.

Material examined. Zhejiang Province, Tianmushan Natural Conservation area $\left(30^{\circ} 12^{\prime}\right.$ N, 119 $23^{\prime}$ E), light trap, 4 males, 12.XI.1998, H. Wu leg.

Diagnostic characters. This species can be separated from other members of the genus by having broad and roughly rectangular inferior volsella, costa not extending the tip of $\mathrm{R}_{4+5}$.

Description. Measurements ( $n=4$ males). Total length 2.13-2.70, $2.38 \mathrm{~mm}$. Wing length 1.70 $1.90,1.83 \mathrm{~mm}$. Total length / wing length 1.12 1.44, 1.31. Antenna with 13 flagellomeres; AR $1.37-1.78,1.57$. VR 1.00-1.07, 1.04. R with 1114,12 setae, $R_{1}$ with $0-2$, 1 setae. Anal point slender, about 50-53, $51 \mu \mathrm{m}$ long. Laterosternite IX with 5-6, 5 setae. Phallapodeme 66-80, $72 \mu \mathrm{m}$ long; transverse sternapodeme 88-125, $101 \mu \mathrm{m}$ long. Anal point slender, tapering. Virga slender, with thin spines, about $30 \mu \mathrm{m}$ long. Gonocoxite 150-170, $161 \mu \mathrm{m}$ long. Gonostylus simple, 48- 
53, $51 \mu \mathrm{m}$ long, widest in the middle. Megaseta $10 \mu \mathrm{m}$ long. HR 3.08-3.40, 3.20; HV 4.01-5.62, 4.76 .

Distribution. Recorded in Japan (Sasa, Kawai \& Ueno, 1988). Occurs in Oriental (Zhejiang province) China.

Remarks. This species has been described in detail by Sasa, Kawai \& Ueno (1988), and this is the first record from China. It should be mentioned that specimen from Japan has no costal extension and an AR of 2.27, while the $\mathrm{C}$ extension and the AR of the Chinese specimen are $25 \mu \mathrm{m}$ and $1.37-1.78$, respectively.

\subsection{Chaetocladius tibetensis}

Wang, Kong \& Wang, sp. n. Fig. 2

Type material. Holotype male (BDN No. 1252), CHINA: Tibet, Naqu Region, Zayu Town $\left(28^{\circ} 38^{\prime} \mathrm{N}, 97^{\circ} 30^{\prime} \mathrm{E}\right)$, sweeping net, 28.V.1987, C. Deng leg.

Diagnostic characters. Just as $C$. orientalis Chaudhuri \& Ghosh, 1982 and C. artistylus Bhattacharyay \& Chaudhuri, 1993, the new species also has a very narrow gonostylus. The most obvious characteristic by which the new species can be separated from those two and from other members of this genus is the virga with a symmetrically hooks-shaped end, which is unique in this genus. In addition, the new species has a longer anal point than $C$. artistylus ( 65 vs. $36 \mu \mathrm{m})$, and C. artistylus has a broader inferior volsella.

Description. Measurements ( $n=1$ male). Total length $3.46 \mathrm{~mm}$. Wing length $2.58 \mathrm{~mm}$. Total length / wing length 1.34. Wing length / length of profemur 2.29.

Coloration. Head black. Thorax and abdomen blackish brown. Wing nearly transparent.

Head. AR 0.49. Temporal setae 14 including 1 inner verticals, 6 outer verticals and 7
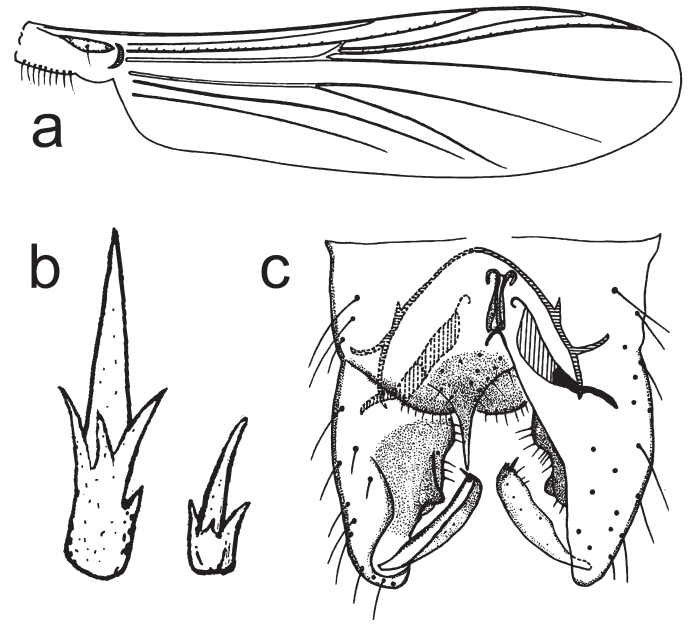

Fig. 2. Chaetocladius tibetensis Wang, Kong \& Wang, sp. n. - a. Wing. - b. Spurs of posterior tibia. - c. Hypopygium.

postorbitals. Clypeus with 8 setae. Tentorium 141 $\mu \mathrm{m}$ long, 44 wide. Palpomere lengths (in $\mu \mathrm{m}$ ): 26 , $44,154,97,224$. Length ratio of palpomeres $5 / 3$ 1.45 .

Wing (Fig. 2a). Scarcely punctate. VR 1.05. Costal extension $30 \mu \mathrm{m}$ long. $\mathrm{R}$ with 23 setae, $\mathrm{R}_{1}$ with 8 setae, $R_{4+5}$ with 29 setae. Brachiolum with 1 setae. Squama with 9 setae.

Thorax. Dorsocentrals 19, acrostichals 5, prealars 4, scutellars 7 .

Legs. Spur of fore tibia $70 \mu \mathrm{m}$ long, of mid tibia $35 \mu \mathrm{m}$ and $22 \mu \mathrm{m}$ long, of hind tibia (Fig. 2b) $70 \mu \mathrm{m}$ and $25 \mu \mathrm{m}$ long, lateral denticles strong. Tibial comb $75 \mu \mathrm{m}$ long. Pseudospur of mid ta 20 $\mu \mathrm{m}$ and $24 \mathrm{~mm}$ long, of ta $22 \mu \mathrm{m}$ and $26 \mathrm{~mm}$ long, of hind ta $19 \mu \mathrm{m}$ and $24 \mu \mathrm{m}$ long, of ta 14 $\mu \mathrm{m}$ and $28 \mu \mathrm{m}$ long. Width at apex of fore tibia 50 $\mu \mathrm{m}$, of mid tibia $48 \mu \mathrm{m}$, of hind tibia $50 \mu \mathrm{m}$. Lengths (in $\mu \mathrm{m}$ ) and proportions of legs in Table 3.

Hypopygium (Fig. 2c). Anal point slender 65 $\mu \mathrm{m}$ long, $50 \mu \mathrm{m}$ wide at the base, with 14 setae on

Table 3. Lengths (in $\mu \mathrm{m}$ ) and proportions of leg segments of male Chaetocladius tibetensis Wang, Kong \& Wang, sp. n. For abbreviations, see Table 1.

\begin{tabular}{|c|c|c|c|c|c|c|c|c|c|c|c|}
\hline & fe & $\mathrm{ti}$ & $\mathrm{ta}_{1}$ & $\mathrm{ta}_{2}$ & $\mathrm{ta}_{3}$ & $\mathrm{ta}_{4}$ & $\mathrm{ta}_{5}$ & LR & BV & SV & $\mathrm{BR}$ \\
\hline$p_{1}$ & 550 & 625 & 400 & 200 & 125 & 75 & 50 & 0.64 & 2.81 & 2.47 & 2.30 \\
\hline $\mathrm{p}_{2}$ & 575 & 500 & 225 & 125 & 100 & 50 & 50 & 0.45 & 3.51 & 4.13 & 2.27 \\
\hline $\mathrm{p}_{3}$ & 550 & 600 & 375 & 200 & 125 & 75 & 50 & 0.63 & 3.27 & 3.26 & 2.67 \\
\hline
\end{tabular}


it. Laterosternite IX with 10 setae. Phallapodeme $70 \mu \mathrm{m}$ long; transverse sternapodeme $130 \mu \mathrm{m}$ long. Virga $70 \mu \mathrm{m}$ long, with symmetrically hooks-shaped end. Gonocoxite $176 \mu \mathrm{m}$ long. Inferior volsella double, with 10 long setae on the big one, and the small one bare. Gonostylus 70 $\mu \mathrm{m}$ long. Megaseta $11 \mu \mathrm{m}$ long. HR 2.51, HV 4.94 .

Distribution. Collected in Tibet Autonomous Region in Oriental China.

Etymology. Named after the type locality (Tibet).

\subsection{Chaetocladius triquetrus}

Wang, Kong \& Wang, sp. n. Fig. 3

Type material. Holotype male (BDN No. 07183), CHINA: Liaoning Province, Dandong City, Kuandian Autonomous County $\left(40^{\circ} 43^{\prime} \mathrm{N}\right.$, 1244ㄱ' E), 22.IV.1992, light trap, J. Wang leg.

Diagnostic characters. Some species also have virga consisting of long spines, such as $C$. elegens Makarchenko \& Makarchenko, 2001 and C. unicus Makarchenko \& Makarchenko, 2001, while the new species can be separated from them by having virga with four long divergent spines, VR lower, squama with 28 setae.

Description. Measurements ( $n=1$ male). Total length $3.50 \mathrm{~mm}$.Wing length $2.13 \mathrm{~mm}$. Total length / wing length 1.65. Wing length / length of profemur 2.69.

Coloration. Head, thorax and abdomen black. Legs blackish brown. Wing nearly transparent.

Head. AR 2.00. Temporal setae including 3 inner verticals, others not clear. Clypeus with 10 setae. Tentorium $140 \mu \mathrm{m}$ long, $25 \mu \mathrm{m}$ wide. Palpomere lengths (in $\mu \mathrm{m}$ ): 25, 75, 140, 100, 150. Length ratio of palpomeres 5/3 1.07.

Wing (Fig. 3a). Scarcely punctate. Anal lobe slightly reduced. VR 0.94 . Costal extension 30
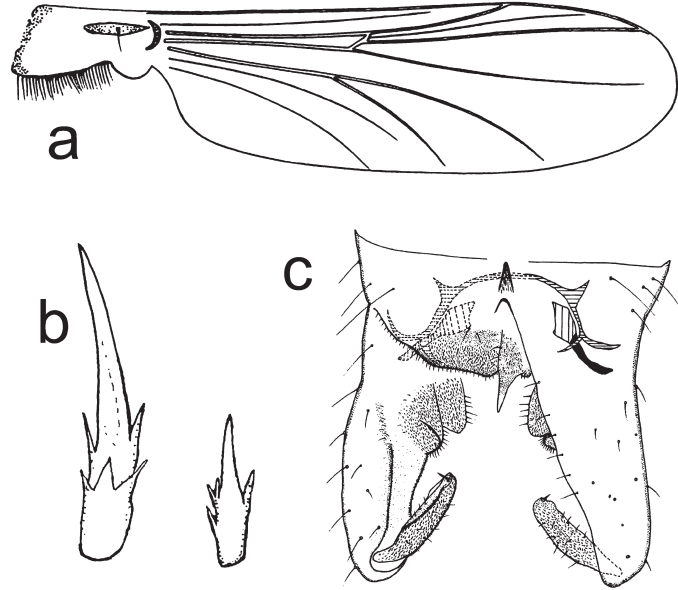

Fig. 3. Chaetocladius triquetrus Wang, Kong \& Wang, sp. n. - a. Wing. - b. Spurs of posterior tibia. - c. Hypopygium.

$\mu \mathrm{m}$ long. Brachiolum with 1 setae. Squama with 28 setae.

Thorax. Dorsocentrals 12; acrostichals 7; prealars 6; scutellars 4 .

Legs. Spur of fore tibia $53 \mu \mathrm{m}$ long; of mid tibia $18 \mu \mathrm{m}$ and $23 \mu \mathrm{m}$ long; of hind tibia (Fig. 3b) $61 \mu \mathrm{m}$ and $22 \mu \mathrm{m}$ long, lateral denticles strong. Tibial comb $53 \mu \mathrm{m}$ long. Pseudospur of mid ta 25 $\mathrm{mm}$ and $32 \mathrm{~mm}$ long, of ta $26 \mathrm{~mm}$ and $33 \mathrm{~mm}$ long, of hind ta $30 \mathrm{~mm}$ and $37 \mathrm{~mm}$ long, of ta 20 $\mathrm{mm}$ and $30 \mathrm{~mm}$ long. Width at apex of fore tibia $50 \mu \mathrm{m}$, of mid tibia $44 \mu \mathrm{m}$, of hind tibia $66 \mu \mathrm{m}$. Lengths (in $\mu \mathrm{m}$ ) and proportions of legs in Table 4.

Hypopygium (Fig. 3c). Anal point $92 \mu \mathrm{m}$ long. Tergite IX with 18 setae. Laterosternite IX with 7 setae. Phallapodeme $105 \mu \mathrm{m}$ long; transverse sternapodeme $120 \mu \mathrm{m}$ long. Virga $35 \mu \mathrm{m}$ long, apparently with 4 long, divergent spines. Gonocoxite $233 \mu \mathrm{m}$ long. Inferior volsella double, each lobe of nearly the same size, with 16 setae. Gonostylus $88 \mu \mathrm{m}$ long, with low and short

Table 4. Lengths (in $\mu \mathrm{m}$ ) and proportions of leg segments of male Chaetocladius triquetrus Wang, Kong \& Wang, sp. n. For abbreviations, see Table 1.

\begin{tabular}{|c|c|c|c|c|c|c|c|c|c|c|c|}
\hline & fe & $\mathrm{ti}$ & $\mathrm{ta}_{1}$ & $\mathrm{ta}_{2}$ & $\mathrm{ta}_{3}$ & $\mathrm{ta}_{4}$ & $\mathrm{ta}_{5}$ & LR & BV & SV & $\mathrm{BR}$ \\
\hline$p_{1}$ & 790 & 1,075 & 640 & 400 & 260 & 180 & 110 & 0.60 & 2.64 & 2.91 & 3.00 \\
\hline$p_{2}$ & 900 & 910 & 440 & 250 & 175 & 120 & 110 & 0.48 & 3.44 & 4.11 & 2.60 \\
\hline $\mathrm{p}_{3}$ & 950 & 1,100 & 600 & 360 & 250 & 140 & 80 & 0.55 & 3.19 & 3.42 & 2.83 \\
\hline
\end{tabular}


crista dorsalis. Megaseta $13 \mu \mathrm{m}$ long. HR 2.65, HV 3.98.

Distribution. Collected in Liaoning province in Palaearctic China.

Etymology. From Latin, triquetrus, triangular, referring to the divergent virgal spines.

\section{Key to adult males of Chinese Chaetocladius}

1. Anal point bare, gonostylus with convex lateral margin

- Anal point with short setae, gonostylus without convex lateral margin

C. oyabevenustus Sasa \& Okazawa

2. $\mathrm{AR}<1.0$, gonostylus obviously narrow or slender

C. tibetensis Wang, Kong \& Wang, sp.n.

- $\mathrm{AR}>1.5$, gonostylus not narrow or slender 3

3. Anal lobe well developed

- Anal lobe not developed or reduced

C. triquetrus Wang, Kong \& Wang, sp. n.

4. Inferior volsella semicircular, anal point 50 $\mu \mathrm{m}$ long

C. absolutus Wang, Kong \& Wang, sp. n.

- Inferior volsella small, not semicircular, anal point less than $50 \mu \mathrm{m}$ long

\section{C. dentiforceps Edwards}

Acknowledgements. Financial support received from the National Natural Science Foundation of China (NSFC) grant No. 30770249, 30870329, J0630963, Fauna of China (FY120100) and Zhejiang Provincial Natural Science Foundation of China (Y3100486) are thankfully acknowledged.

\section{References}

Ashe, P. \& Cranston, P. S. 1990: Family Chironomidae. In: Soós, Á. \& Papp, L. (eds.), Catalogue of Palaearctic Diptera, vol. 2: Psychodidae-Chironomidae: 113355. Akad. Kiadó, Budapest.

Bhattacharyay, S., Chattopadhyay, S. \& Chaudhuri, P. K. 1993: Four new species of Chaetocladius (Diptera, Chironomidae) from India. - European Journal of Entomology 90: 87-94.

Brundin, L. 1947: Zur Kenntnis der schwedischen Chironomiden. - Arkiv för Zoologi 39A, 3:1-95.

Chaudhuri, P. K. \& Ghosh, M. 1982: Record of Chaetocladius Kieffer (Diptera: Chironomidae) from India. Folia Entomologica Hungarica 63: 5-7.
Chaudhuri, P. K., Hazra, N. \& Alfred, J. R. B. 2001: A checklist of chironomid midges (Diptera: Chironomidae) of the Indian subcontinent. - Oriental Insects 35: 335-372.

Coffman, W. P., Cranston, P. S., Oliver, D. R. \& Sæther, O. A. 1986: The pupae of Orthocladiinae (Diptera: Chironomidae) of the Holarctic region - Keys and diagnoses. - In: Wiederholm, T. (ed.), Chironomidae of the Holarctic region. Keys and diagnoses. Part 2 - Pupae. Entomologica scandinavica Supplement 28: 147-296.

Cranston, P. S., Oliver, D. R. \& Sæther, O. A. 1983: The larvae of Orthocladiinae (Diptera: Chironomidae) of the Holarctic region - Keys and diagnoses. - In: Wiederholm, T. (ed.), Chironomidae of the Holarctic region. Keys and diagnoses. Part 1 - Larvae. - Entomologica scandinavica Supplement 19: 149-291.

Cranston, P. S. \& Martin, J. 1989: Family Chironomidae. - In: Evenhuis, N. L. (ed.), Catalog of the Diptera of the Australasian and Oceanic Regions: 252-274. Bishop Mus. Pr., Honolulu, and E. J. Brill, Leiden.

Edwards, F. W. 1929: British non-biting midges (Diptera, Chironomidae). - Transactions of the Royal Entomological Society of London 77: 279-430.

Harrison, A. D. 1992: Chironomidae from Ethiopia, Part 2. Orthocladiinae with two new species and a key to Thienemanniella Kieffer (Insecta, Diptera). — Spixiana 15: 149-195.

Kieffer, J. J. 1911: Diptera, Chironomidae der SeychellenInseln, aus der Sammlung von Mr H. Scott. - Transactions of the Linnean Society of London. $2^{\text {nd }}$ Series: Zoology 14: 331-366.

Makarchenko, E. A \& Makarchenko, M. A. 2000: A Review of the Chironomidae (Diptera) from the Kuril Islands, Kamchatka Peninsula and bordering territories. - Results of recent research on North East Asian biota. Natural History Research Special Issue 7: 181197.

Makarchenko, E.A. \& Makarchenko, M.A. 2001: Fauna chironomid podsemeistva Orthocladiinae (Diptera, Chironomidae) ostrova Vrangelya. (Chironomid fauna of the subfamily Orthocladiinae (Diptera, Chironomidae) of Wrangel Island.). - In: Chteniya pamyati Vladimira Yakovlevicha Levanidova (V. Y. Levanidov's Biennial Memorial Meeting) 1: 174-186.

Makarchenko E.A., Makarchenko M.A. 2004: Chaetocladius Kieffer (Diptera, Chironomidae, Orthocladiinae) in the Russian Far East. - Euroasian Entomological Journal 3: 311-317 [In Russian.]

Makarchenko E.A. \& Makarchenko M.A. 2011: Fauna and distribution of the Orthocladiinae of the Russian Far East. - In: Wang, X. and Liu, W. (eds.), Contemporary chironomid studies: 107-125. Proceedings of the $17^{\text {th }}$ International Symposium on Chironomidae (July 6-9, 2009 Nankai University, China). Nankai University Press.

Oliver, D. R., Dillon, M. E. \& Cranston, P. S. 1990: A cata$\log$ of Nearctic Chironomidae. - Research Branch Agriculture Canada Publication 1857: 1-89.

Sasa, M., Kawai, K. \& Ueno, R. 1988: Studies on the chironomid midges of Oyabe River, Toyama, Japan. In: 
Some Characteristics of Nature Conservation within the Chief Rivers in Toyama Prefecture (The Upper Reach of Oyabe River). - Research Report from Toyama Prefectural Environmental Pollution Research Centre 1988: 26-85.

Sasa, M. \& Okazawa, T. 1992: Studies on the chironomid midges (yusurika) of Toga Mura, Toyama. Part 2. The subfamily Orthocladiinae. - Research Report from Toyama Prefectural Environmental Pollution Research Centre 1992: 92-204.

Sæther, O. A. 1969: Some Nearctic Podonominae, Diamesinae, and Orthocladiinae (Diptera: Chironomidae). - Bulletin of the Fisheries Research Board of Canada 170: 1-154.

Sæther, O. A. 1980: Glossary of chironomid morphology terminology (Diptera: Chironomidae). — Entomologica scandinavica Supplement 14: 51.

Sæther, O. A. 1986: On the systematic positions of Dolichoprymna, Amblycladius and Kloosia (Diptera: Chironomidae). - Abstracts of First International Congress of Dipterology (ISBN 9637251 626): 215.
Stur, E. \& Spies, M. 2011: Description of Chaetocladius longivirgatus sp. n., with a review of $C$. suecicus (Kieffer) (Diptera: Chironomidae). - Zootaxa 2762: 37-48.

Sublette, J. E. \& Sublette, M. S. 1973: Family Chironomidae. - In: Delfinado, M. \& Hardy, E. D. (eds.), Catalogue of the Diptera of the Oriental Region 1: 389 422.

Thienemann, A. \& Kieffer, J. J. 1916: Schwedische Chironomiden. - Archiv für Hydrobiologie, Supplement 2: 483-554.

Wang, X. 2000: A revised checklist of Chironomidae from China (Diptera). - In: Hoffrichter, O. (ed.), Late $20^{\text {th }}$ Century Research on Chironomidae. An Anthology from the $13^{\text {th }}$ International Symposium on Chironomidae: 629-652. Shaker Verlag, Achen.

Yamamoto, M. 2004: A catalog of Japanese Orthocladiinae (Diptera: Chironomidae). — Makunagi, Acta dipterologica 21: 1-121. 